\title{
Green living environment protects against allergy, or does it?
}

\author{
Lasse Ruokolainen
}

Affiliation: Dept of Biosciences, University of Helsinki, Helsinki, Finland.

Correspondence: Lasse Ruokolainen, Dept of Biosciences, University of Helsinki, Viikinkaari 1, FIN-00014 Helsingin yliopisto, Finland. E-mail: lasse.ruokolainendahelsinki.fi

@ERSpublications

We need more direct and accurate measures to assess the quality and amount of environmental exposure http://ow.ly/McGd30c4Aww

Cite this article as: Ruokolainen L. Green living environment protects against allergy, or does it? Eur Respir J 2017; 49: 1700481 [https://doi.org/10.1183/13993003.00481-2017].

Increasing human populations impose enormous pressure on natural habitats. For example, forests around the world are being converted into timber, pastures, croplands and settlements. To put the rate of deforestation into context, an area equivalent of $\sim 50$ football fields is destroyed every minute [1]. While this development is one of the most important threats to biological diversity, human health is also at stake. In 2011, it was suggested that the global loss of biodiversity might be related to the parallel increase in the incidence of inflammatory disorders [2]. This gave rise to the biodiversity hypothesis of allergic disease [3] proposing that contact with natural environments enriches the human microbiome, promotes immune balance and protects from inflammatory disorders. The biodiversity hypothesis enlarges the Old Friends mechanism, emphasising the co-evolutionary history between humans and immunoregulatory microbes [4].

Allergic disease is increasingly prevalent in Western countries, but now rapidly developing countries, such as India and China [5], are also facing the allergy epidemic that became evident in industrialised Europe some 40 years ago $[6,7]$. We have compared the prevalence of allergic disease both among children and adults living in Finnish and Russian Karelia. These adjacent areas show one of the most contrasting socioeconomic differences in the world, and at the same time, a striking difference in the prevalence of inflammatory disorders [8]. Interestingly, the recent adolescent study cohorts also showed clear differences in their skin and nasal microbial composition (figure 1a) and diversity, which were higher among Russian than Finnish subjects [9], potentially linking the differences in lifestyle to immunological tolerance. At a smaller scale, the living environment can affect skin microbial composition (figure 1b) [11], which potentially contributes to the observed differences in health [12]. Even the diversity of the indoor microbiota might be associated with the risk of allergic disease. This is supported by observations that the indoor microbiota depends on housing conditions [13], as well as the composition and behaviour of the household members $[14,15]$.

\section{Conflicting heath-environment associations}

While exposure to beneficial microbes is essential, the complexity of different exposure routes makes studying the biodiversity hypothesis challenging [16]. One way of finding indirect evidence has been to investigate the composition of the immediate living environment in association with health, which makes sense in the light that airborne bacterial communities can differ considerably between different land use

Received: March 082017 | Accepted after revision: May 212017

Support statement: I would like to thank the Academy of Finland for funding. Funding information for this article has been deposited with the Crossref Funder Registry.

Conflict of interest: None declared

Copyright CERS 2017 
a)

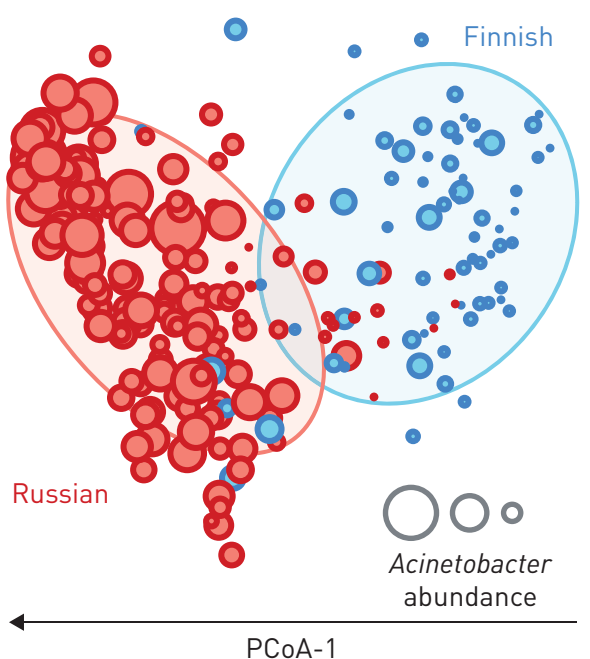

b) $\quad$ -

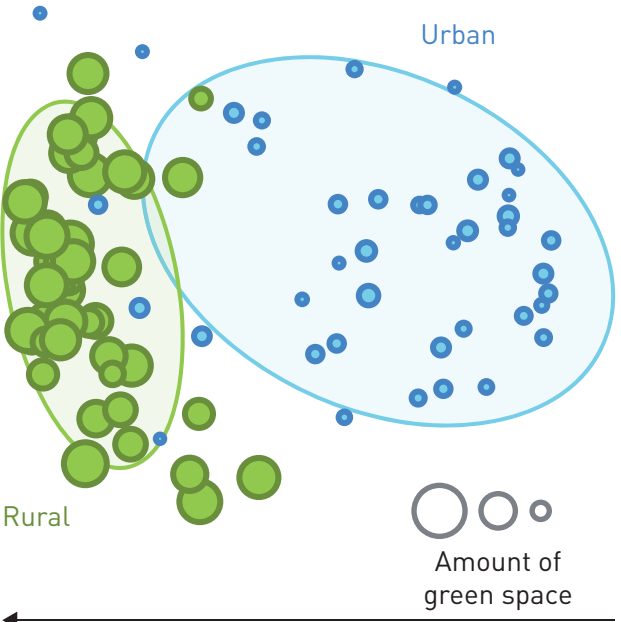

PCoA-1

FIGURE 1 Living environment and lifestyle affect the composition of the human exterior microbiota. a) Differences in nasal microbiota between adolescents from Finnish and Russian Karelia, where the symbol size indicates the abundance of Acinetobacter operational taxonomic units in the samples. Data from [9]. These bacteria, best characterising differences in community composition, might have important immunoregulatory potential [10]. b) Differences in skin microbiota between urban and rural children (2-4 years old), where the symbol size shows the relative amount of green space (forest and agricultural land within a 3-km buffer around the homel in the living environment around homes, indicating that the skin microbiota might reflect the living environment. Data from [11]. The figures show principal coordinates plots based on sample proximities from random forest classifications. The ellipses indicate $75 \%$ concentration of points within groups. PCoA: principal coordinate analysis.

types $[15,17]$. This approach has demonstrated negative associations between increasing amount of green space and allergic sensitisation [12, 18], generalising earlier reports comparing rural and urban cohorts (e.g. that by MajкоWsка-Wojciechowsкa et al. [19]); it should be kept in mind that associations between health and the living environment can be age-specific due to the development of allergic manifestation in children [12]. However, conflicting results have also been reported [20], begging the question, why do we not always observe a protective effect of green space?

Tischer et al. [21], as reported in this issue of the European Respiratory Journal, investigated the association between respiratory health and the availability and accessibility of green space in the living environment. They studied a birth cohort of $\sim 2500$ children in two biogeographical regions in Spain with distinct climates and vegetation patterns. The Euro-Siberian region covers a narrow ridge across the northern part of the Iberian Peninsula. This region is characterised by an Atlantic climate with relatively cold winters and maximum vegetation during the summer months. In contrast, the Mediterranean region is characterised by a dry climate with hot, dry summers; mild, rainy winters; and maximum vegetation during autumn and spring. To estimate environmental exposure, they measured residential surrounding greenness and residential proximity to green spaces. These two measures are likely to be complementary, as surrounding greenness does not necessarily imply access to green space. Residential surrounding greenness was based on the satellite-derived Normalised Difference Vegetation Index (NDVI), whereas residential proximity to green spaces was estimated from the Urban Atlas map developed by the European Environment Agency. Importantly, they also reported the correlation between these two indices, as well between them and surrounding "grey" areas (built environment) and nitrogen dioxide emissions (a proxy for pollution exposure).

They found that health outcomes were differentially associated with the living environment in these two study regions. Higher residential surrounding greenness and higher proximity to green spaces were associated with reduced risk for wheezing in the Euro-Siberian but not in the Mediterranean region. In contrast, higher residential proximity to green spaces was associated with a reduced risk for bronchitis in the Mediterranean region but not in the Euro-Siberian region. Such inconsistent results were reported also by Fuertes et al. [22], studying two birth cohorts in northern and southern Germany. They found that in the urban south, green space (the NDVI in the immediate living environment) was positively associated with allergic rhinitis and eye and nose symptoms, while in the rural north, green space appeared to have a protective effect. In a more extensive follow-up, FuERTEs et al. [20] studied cohorts from Australia, Canada, 
Germany, the Netherlands and Sweden, again with inconclusive results. However, they were unable to pinpoint any specific reason for their conflicting findings.

\section{What might confound the observation of positive environment-health relationships?}

As noted above, simply quantifying the proportion of green space around homes is only an indirect way of assessing exposure. The spatial scale of this assessment can further affect the ability to uncover associations between health and the living environment [12]. This means that we need more direct measures to assess the quality and amount of environmental exposure. While green space can promote health in many different ways [23-25], microbes are probably the most important immunoregulatory effectors in Western societies (e.g. the study by LoGAN et al. [26]). Thus, we need to understand better the process of microbial colonisation from the environment to different individuals and to the different body sites of the same individual [27], which might differ between regions [11].

When comparing regions, we should also know how well the surrounding greenness is actually associated with exposure to the environment. Cultural and behavioural differences, varying characteristics of landscape structure and vegetation type, and pollution can all have an effect [11, 20,21, 28]. Contact and exposure are also likely to depend on the quality of the surrounding green space [24]. Globally, time spent indoors is likely to vary considerably between warm and cold climates but might also differ between rural and urban communities or even depending on the surrounding green space [29]. This affects the relative exposure to indoor and outdoor microbiota, which tend to differ considerably [15]. The indoor microbiota is strongly influenced by the number and type of occupants living in the homes: the female/male ratio and pets in the household significantly influence the types of bacteria found inside. It is also possible that other protective or predisposing factors mask the role of the living environment [12, 24]. For example, sufficient exposure to high levels of certain allergens and bacteria in early life might protect against allergies even in inner-city environments [30], while, for example, Caesarean section [27], air pollution [25] or tobacco smoke exposure [31] predispose to allergies in general. Finally, the timing and extent of exposure is also likely to make a difference: early-life exposure seems especially important [16], which means that movement of study subjects between locations can become a confounding factor [12].

\section{Conclusions and implications for future work}

For the development of balanced immune tolerance, exposure to a diverse microbial environment is important in early life (e.g. the study by ARRIETA et al. [32]). While antibiotics and a western diet reduce the diversity of gut microbial communities [27], diversity can be promoted by colonisation from a rich microbial environment $[13,33]$. In humans, environmental microbes readily colonise the skin and airways, habitats where microbial composition has been shown to depend on the living environment and lifestyle (figure 1) $[8,11]$. Moreover, the composition of the skin and nasal microbiota can have a systemic influence on host health [10,34], similar to the gut microbiota [35], which can also be influenced by the environment [30,36].

Promoting contact with nature and overall environmental exposure should be emphasised not only in small children but also in other groups due to manifold health benefits [24]. While this should be taken into consideration in urban planning [23], our daily choices also matter [16]. In epidemiological studies, the relative importance of early childhood on immune development is also a confounding factor. In cross-sectional settings, the current living environment may not reflect environmental exposure early in life $[11,28]$ and it is also unknown what is the relative importance of early versus later exposure. This should be taken into account not only when interpreting results from previous work but also when planning new studies on the association between the living environment and health. We need longitudinal studies and knowledge of the mechanisms of microbial transmission from environment to humans. Ideally, lifestyle factors should be controlled for but as this might be practically very difficult, animal models will still remain an important tool for investigating environment-health associations [33, 37].

\section{Acknowledgements}

I would like to thank Tari Haahtela and an anonymous reviewer for their comments to improve the manuscript.

\section{References}

1 World Wildlife Fund. Deforestation. https://www.worldwildlife.org/threats/deforestation Date last accessed: May 30, 2017. Date last updated: 2017.

2 von Hertzen L, Hanski I, Haahtela T. Natural immunity. Biodiversity loss and inflammatory diseases are two global megatrends that might be related. EMBO Rep 2011; 12: 1089-1093.

3 Haahtela T, Holgate S, Pawankar R, et al. The biodiversity hypothesis and allergic disease: World Allergy Organization position statement. World Allergy Organ J 2013; 6: 3. 
4 Rook GAW. 99th Dahlem Conference on Infection, Inflammation and Chronic Inflammatory Disorders: Darwinian medicine and the 'hygiene' or 'old friends' hypothesis. Clin Exp Immunol 2010; 160: 70-79.

5 Wang XD, Zheng M, Lou HF, et al. An increased prevalence of self-reported allergic rhinitis in major Chinese cities from 2005 to 2011. Allergy 2016; 71: 1170-1180.

6 Jousilahti P, Haahtela T, Laatikainen T, et al. Asthma and respiratory allergy prevalence is still increasing among Finnish young adults. Eur Respir J 2016; 47: 985-987.

7 Wong GWK, Leung TF, Ko FWS. Changing prevalence of allergic diseases in the Asia-Pacific region. Allergy Asthma Immunol Res 2013; 5: 251-257.

8 Haahtela T, Laatikainen T, Alenius $\mathrm{H}$, et al. Hunt for the origin of allergy - comparing the Finnish and Russian Karelia. Clin Exp Allergy 2015; 45: 891-901.

9 Ruokolainen L, Paalanen L, Karkman A, et al. Significant disparities in allergy prevalence and microbiota between the young people in Finnish and Russian Karelia. Clin Exp Allergy 2017; 47: 665-674.

10 Fyhrquist N, Ruokolainen L, Suomalainen A, et al. Acinetobacter species in the skin microbiota protect against allergic sensitization and inflammation. J Allergy Clin Immunol 2014; 134: 1301-1309.

11 Lehtimäki J, Karkman A, Laatikainen T, et al. Patterns in the skin microbiota differ in children and teenagers between rural and urban environments. Sci Rep 2017; 7: 45651.

12 Ruokolainen L, von Hertzen L, Fyhrquist N, et al. Green areas around homes reduce atopic sensitization in children. Allergy 2015; 70: 195-202.

13 Birzele LT, Depner M, Ege MJ, et al. Environmental and mucosal microbiota and their role in childhood asthma Allergy 2017; 72: 109-119.

14 Lax S, Nagler CR, Gilbert JA. Our interface with the built environment: immunity and the indoor microbiota. Trends Immunol 2015; 36: 121-123.

15 Barberán A, Dunn RR, Reich BJ, et al. The ecology of microscopic life in household dust. Proc R Soc B 2015; 282: 20151139.

16 Ruokolainen L, Fyhrquist N, Haahtela T. The rich and the poor: environmental biodiversity protecting from allergy. Curr Opin Allergy Clin Immunol 2016; 16: 421-426.

17 Mhuireach G, Johnson BR, Altrichter AE, et al. Urban greenness influences airborne bacterial community composition. Sci Total Environ 2016; 571: 680-687.

18 Hanski I, von Hertzen L, Fyhrquist N, et al. Environmental biodiversity, human microbiota, and allergy are interrelated. Proc Natl Acad Sci USA 2012; 109: 8334-8339.

19 Majkowska-Wojciechowska B, Pełka J, Korzon L, et al. Prevalence of allergy, patterns of allergic sensitization and allergy risk factors in rural and urban children. Allergy 2007; 62: 1044-1050.

20 Fuertes E, Markevych I, Bowatte G, et al. Residential greenness is differentially associated with childhood allergic rhinitis and aeroallergen sensitization in seven birth cohorts. Allergy 2016; 71: 1461-1471.

21 Tischer C, Gascon M, Fernández-Somoano A, et al. Urban green and grey space in relation to respiratory health in children. Eur Respir J 2017; 49: 1502112.

22 Fuertes E, Markevych I, von Berg A, et al. Greenness and allergies: evidence of differential associations in two areas in Germany. J Epidemiol Community Health 2014; 68: 787-790.

23 Wolch JR, Byrne J, Newell JP. Urban green space, public health, and environmental justice: the challenge of making cities “just green enough". Landsc Urban Plan 2014; 125: 234-244.

24 WHO. Urban Green Spaces and Health - a Review of Evidence. Copenhagen, WHO Regional Office for Europe, 2016

25 Gascon M, Vrijheid M, Nieuwenhuijsen MJ. The built environment and child health: an overview of current evidence. Curr Environ Health Rep 2016; 3: 250-257.

26 Logan AC, Jacka FN, Prescott SL. Immune-microbiota interactions: dysbiosis as a global health issue. Curr Allergy Asthma Rep 2016; 16: 1-9.

27 Karkman A, Lehtimäki J, Ruokolainen L. The ecology of human microbiota: dynamics and diversity in health and disease. Ann NY Acad Sci 2017 [in press https://doi.org/10.1111/nyas.13326].

28 Ruokolainen L, Lehtimäki J, Karkman A, et al. Holistic view on health: two protective layers of biodiversity. Ann Zool Fenn 2017; 54: 39-49.

29 Dadvand P, Villanueva CM, Font-Ribera L, et al. Risks and benefits of green spaces for children: a cross-sectional study of associations with sedentary behavior, obesity, asthma, and allergy. Environ Health Perspect Online Res Triangle Park 2014; 122: 1329.

30 Lynch SV, Wood RA, Boushey H, et al. Effects of early-life exposure to allergens and bacteria on recurrent wheeze and atopy in urban children. J Allergy Clin Immunol 2014; 134: 593-601.

31 Feleszko W, Ruszczyński M, Jaworska J, et al. Environmental tobacco smoke exposure and risk of allergic sensitisation in children: a systematic review and meta-analysis. Arch Dis Child 2014; 99: 985-992.

32 Arrieta M-C, Stiemsma LT, Dimitriu PA, et al. Early infancy microbial and metabolic alterations affect risk of childhood asthma. Sci Transl Med 2015; 7: 307ra152.

33 Müller VM, Zietek T, Rohm F, et al. Gut barrier impairment by high-fat diet in mice depends on housing conditions. Mol Nutr Food Res 2016; 60: 897-908.

34 Kennedy EA, Connolly J, Hourihane JO, et al. Skin microbiome before development of atopic dermatitis: early colonization with commensal staphylococci at 2 months is associated with a lower risk of atopic dermatitis at 1 year. J Allergy Clin Immunol 2017; 139: 166-172.

35 Fujimura KE, Lynch SV. Microbiota in allergy and asthma and the emerging relationship with the gut microbiome. Cell Host Microbe 2015; 17: 592-602.

36 Konya T, Koster B, Maughan H, et al. Associations between bacterial communities of house dust and infant gut. Environ Res 2014; 131: 25-30.

37 Schaub B, Vercelli D. Environmental protection from allergic diseases: From humans to mice and back. Curr Opin Immunol 2015; 36: 88-93. 